\title{
Prognostic significance of nm23-HI expression in oral squamous cell carcinoma
}

\author{
Y-F Wang ${ }^{1,2}$, K-C Chow ${ }^{3}$, S-Y Chang', J-H Chiu', S-K Tai', W-Y Li' ${ }^{5}$ and L-S Wang,6 \\ 'Department of Otolaryngology, Taipei Veterans General Hospital, National Yang-Ming University, Taipei I I 2, Taiwan, ROC; ${ }^{2}$ Institute of Clinical \\ Medicine, National Yang-Ming University, Taipei I 12, Taiwan, ROC; ${ }^{3}$ Institute of Biomedical Sciences, National Chung Hsing University, Taichung 402, \\ Taiwan, ROC; ${ }^{4}$ Institute of Traditional Medicine, National Yang-Ming University, Taipei I I 2, Taiwan, ROC; ${ }^{5}$ Department of Pathology, Taipei Veterans \\ General Hospital, National Yang-Ming University, Taipei I I 2, Taiwan, ROC; ${ }^{6}$ Division of Chest Surgery, Department of Surgery, Taipei Veterans General \\ Hospital and National Yang-Ming University, Taipei I I2, Taiwan, ROC
}

Recent studies indicated $\mathrm{nm} 23-\mathrm{HI}$ played a role in cancer progression. Therefore, we investigated clinical significance of $\mathrm{nm} 23-\mathrm{HI}$ expression in oral squamous cell carcinoma (OSCC). In total, 86 OSCC specimens were immunohistochemically stained with nm23$\mathrm{HI}$-specific monoclonal antibodies. Immunohistochemical staining of $\mathrm{nm} 23-\mathrm{HI}$ was confirmed by immunoblotting. The relations between $\mathrm{nm} 23-\mathrm{HI}$ expression and clinicopathologic variables were evaluated by $\chi^{2}$ analysis. As increased size of primary tumour could escalate metastatic potential and the data of patients at the late $T$ stage might confound statistical analyses, we thus paid special attention to 54 patients at the early $T$ stage of OSCC. Statistical difference of survival was compared by a log-rank test. Immunohistochemically, nm23-HI expression was detected in $48.8 \%$ (42 out of 86 ) of tumorous specimens. It positively correlated with larger primary tumour size $(P=0.03)$ and inversely with cigarette-smoking habit $(P=0.042)$. In patients at the early $T$ stage, decreased nm23 expression was associated with increased incidence of lymph node metastasis $(P=0.004)$ and indicated poor survival $(P=0.014)$. Tumour nm23-HI expression is a prognostic factor for predicting better survival in OSCC patients at the early $T$ stage, which may reflect antimetastatic potential of $\mathrm{nm} 23$. Therefore, modulation of $\mathrm{nm} 23-\mathrm{HI}$ expression in cancer cells can provide a novel possibility of improving therapeutic strategy at this stage. In addition, our results further indicated cigarette smoking could aggravate the extent of $\mathrm{nm} 23-\mathrm{HI}$ expression and possibly disease progression of OSCC patients. British Journal of Cancer (2004) 90, 2186-2193. doi:I0.1038/sj.bjc.6601808 www.bjcancer.com Published online 4 May 2004

(C) 2004 Cancer Research UK

Keywords: oral squamous cell carcinoma (OSCC); nm23; metastasis; prognosis

Oral squamous cell carcinoma (OSCC) is the most common malignant tumour of the oral cavity. The incidence of OSCC differs among the various regions of the world and the relative frequency ranges from less than $0.1 \%$ to over $40 \%$ (Pindborg, 1977; Sankaranarayanan, 1990). In Taiwan, OSCC constitutes a significant portion of all malignancies (Tsay and Chiu, 1990). Since 1991, this disease has been the fifth leading cause of cancer death in males, and the seventh in the whole population (Hsieh et al, 2001).

Despite the curative surgical resection and multitherapeutic modalities, the overall survival has not improved substantially in the last two decades (Zakrzewska, 1999). The major causes of treatment failure are early lymphatic involvement and distant metastasis. It has been reported that more than half of the patients with resectable OSCC had locoregional spreading at diagnosis (Chen et al, 1999; Wang et al, 2002). Moreover, the differential responses between patients with a small oral tumour but evident metastasis having poorer prognosis and those with a large primary lesion but without detectable spreading obtaining better survival suggest a basic mechanism underlying this difference. A biomarker

*Correspondence: Dr L-S Wang; E-mail: Iswang@vghtpe.gov.tw Received 29 September 2003; revised 23 January 2004; accepted 4 March 2004; published online 4 May 2004 that can reflect this mechanism, forecast the status of disease progression and the potential of cancer metastasis would be imperative to commence the optimal treatment and improve survival significantly.

The nm23 gene was originally identified by differentiating cDNA libraries from strongly and weakly metastatic murine melanoma cell lines (Steeg et al, 1988a). Higher expression of nm23 was found in weakly metastatic cells. Further studies confirmed the antimetastatic effect in animal models (Steeg et al, 1988b; Caligo et $a l, 1992$ ) and in human carcinomas (Bevilacqua et al, 1989; Caligo et al, 1997). The consequent protein analysis showed that nm23 not only had the sequence homologous to nucleoside diphosphate kinase (NDPK) but also had NDPK activity to convert nucleoside diphosphates to nucleoside triphosphates with an expense of ATP (Gilles et al, 1991; Cipollini et al, 1997). In human, nm23/NDPK family consists of at least eight homologues (nm23-H1 to nm23-H8) (Lacombe et al, 2000). Among these homologues, $\mathrm{nm} 23-\mathrm{H} 1$ and $\mathrm{nm} 23-\mathrm{H} 2$, sharing an $88 \%$ identity with each other, are further shown closely associated with antimetastatic potential (Stahl et al, 1991). Nonetheless, clinical studies of nm23 expression in various cancers did not fully support such notion. A few clinical results indeed indicated that $\mathrm{nm} 23$ expression, as anticipated from the in vitro investigations, correlated with better prognosis (Bevilacqua et al, 1989; Barnes et al, 1991; Hirayama et al, 1991; Nakayama et al, 1992; Campo 
et al, 1994; Hsu et al, 1999). Results from other studies, on the contrary, suggested that $\mathrm{nm} 23$ might facilitate tumour development and disease progression (Hailat et al, 1991; Zou et al, 1993; Müller et al, 1998; Pavelic et al, 2000). The discrepancy may be due to, in part, the difference of study design and, in part, study end point selected. It is worth noting that tumour development is a multifactorial process, and it is likely that a specific factor might be able to play a certain role only within a defined period of disease progression. At other time, the nature of this specific factor might change.

Expression of nm23 and its clincopathologic significance have not been well established in patients with OSCC. Therefore, in this study, we used immunohistochemical (IHC) method to examine the nm23-H1 expression in surgical specimens of OSCC patients. Expression of $\mathrm{nm} 23-\mathrm{H} 1$ was further confirmed by immunoblotting. Correlations between $\mathrm{nm} 23-\mathrm{H} 1$ and respective clinicopathologic parameters as well as prognostic significance of $n m 23-\mathrm{H} 1$ in OSCC patients were assessed by statistical analysis, in which $\mathrm{nm} 23$ expression was used as the determinant to categorise the functional groups. The biological role of $\mathrm{nm} 23-\mathrm{H} 1$ in OSCC was then deduced following these analyses.

\section{MATERIALS AND METHODS}

\section{Patients and tissue specimens}

From October 1984 to June 1998, clinicopathologic data and tissue specimens from 86 consecutive patients diagnosed as OSCC were collected. All patients were pathologically confirmed OSCC. The preoperative workup consisted of physical examination, intraoral biopsy, computed tomography (CT) scan of head and neck, sonography of the abdomen, chest radiography and radioisotopic bone scan of whole body. All patients underwent surgical resection of tumours. Comprehensive or selective neck dissection was performed for suspected cervical lymphadenopathy or prophylactic neck management (Scully and Porter, 2000). Local irradiation and/or systemic cisplatin-based chemotherapy were postoperatively administered for patients with advanced stages of the disease, insufficient margins $(<2 \mathrm{~cm})$ of curative resection or tumour recurrence. Nevertheless, no patient received neoadjuvant therapy in this cohort. After treatment, all patients were followed routinely. Stages of the disease were categorised based on TNM staging system (Fleming et al, 1997). According to Broders' criteria (Anneroth et al, 1987), differentiation pattern of the malignancy was classified into three histologic grades: well, moderately and poorly differentiated squamous cell carcinoma. Of 86 surgical specimens, 50 were well and 36 were moderately differentiated carcinomas. No poorly differentiated OSCC was detected. Tumour recurrence and metastasis were identified when physical examination, endoscopy, chest radiography, CT scan of head and neck, sonography of the abdomen or radioisotopic bone scan of whole body showed an evidence. If possible, biopsy confirmation was performed. Medical Ethical Committee has approved this protocol and the written informed consent has been obtained from every patient before surgery. A single-blinded procedure was followed for immunohistochemical staining, immunoblotting and statistical analysis.

\section{Immunohistochemical staining}

Expression of $\mathrm{nm} 23-\mathrm{H} 1$ in the pathologic sections was detected by an immunoperoxidase method as previously described (Wang et al, 1999a, 2002). Paraffin blocks were sectioned at the thickness of $4 \mu \mathrm{m}$. The wax was melted at $65^{\circ} \mathrm{C}$ overnight. The sections were deparaffinised in xylene, and xylene was subsequently removed with absolute ethanol. The slides were then incubated with mouse monoclonal antibodies specific to nm23-H1 (Santa Cruz Biotech- nology, CA, USA) and followed by biotin-conjugated goat antimouse immunoglobulin and horseradish peroxidase (HRP)-conjugated streptavidin (DAKO, Glostrup, Denmark). Aminoethylcarbazole was used as chromogenic substrate and red precipitate was identified as positive staining. The specimens were counterstained with haematoxylin and mounted with glycerol gelatin. In each experiment, a section of human breast cancer known to overexpress $\mathrm{nm} 23-\mathrm{H} 1$ was served as a positive control (DAKO, Glostrup, Denmark) and a section without adding the primary antibody was used as a negative control. Each batch of IHC contained the slides of a positive and a negative control to ensure the staining quality.

\section{Slide evaluation of immunohistochemical staining}

Slide evaluation has been described previously (Barnes et al, 1991; Hsu et al, 1999). Briefly, histologically nontumourous epithelium of oral tissue was served as internal negative control in each case. Under the low-power field, each slide was evaluated randomly at 10 different areas containing tumour cells by two independent investigators blinded to the clinicopathologic data. At least 100 tumour cells were examined per field. Two scoring systems, staining intensity and percentage of stained cells, were included in our study (Barnes et al, 1991; Moskaluk, 2002). The staining intensity was scored on a semiquantitative four-point scale as follows: 0 , equivalent to the negative control; 1 , weak cytoplasmic stain slightly darker than the negative control; 2 , moderate stain defined as the intensity between score 1 and 3; 3, intense stain equivalent to or darker than the positive control. We use the photomicrographs of the respective four scales $(0-3)$ as standard comparators while interpreting the slides. When there were more than $25 \%$ of cancer cells with staining intensity scored above $2-3$ (Figure 1), nm23-H1 expression was recorded positive for this patient (Wang et al, 1999b).

\section{Immunoblotting}

IHC staining of nm23-H1 was then confirmed by immunoblotting in part of surgical specimens. Briefly, tissues were washed in phosphate-buffered saline and lysed in loading buffer containing $50 \mathrm{~mm}$ Tris ( $\mathrm{pH} 6.8$ ), $150 \mathrm{~mm} \mathrm{NaCl}, 1 \mathrm{~mm}$ disodium EDTA, $5 \% \beta$ mercaptoethanol, $1 \mathrm{~mm}$ phenylmethylsulphonylfluoride, $0.01 \%$ bromophenol blue, 10\% glycerol and 1\% SDS supplemented with

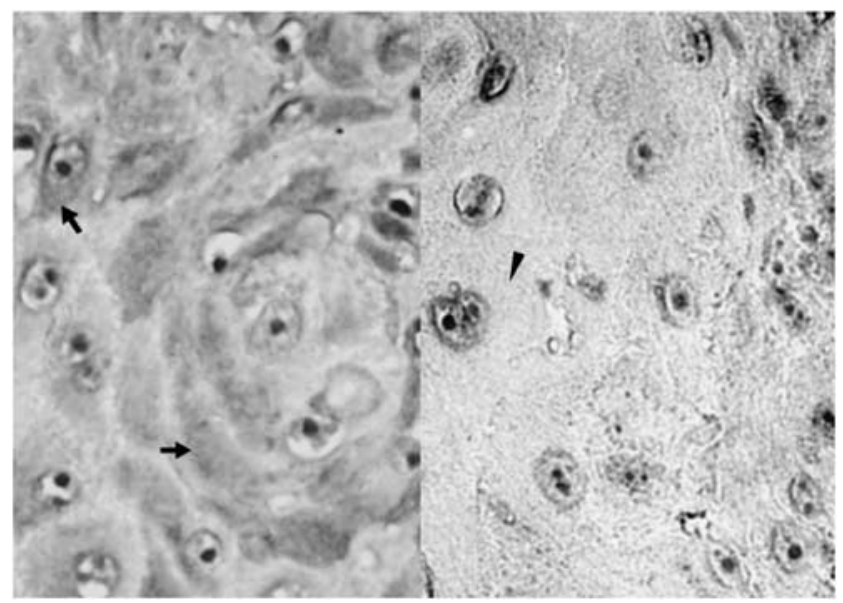

Figure I Immunohistochemical staining for $\mathrm{nm} 23-\mathrm{HI}$ protein in OSCC. Left: Representative example of positive $\mathrm{nm} 23-\mathrm{HI}$ expression, which demonstrated intense $\mathrm{nm} 23-\mathrm{Hl}$ immunoreactivity (arrows) in the cytoplasma of tumour cells. Right: Representative example of negative nm23-HI expression. Arrowhead indicates almost no precipitate in the cytoplasma of tumour cells (original magnification $\times 400$ ). 
leupeptin $\left(10 \mu \mathrm{g} \mathrm{ml}^{-1}\right)$, aprotinin $\left(10 \mu \mathrm{g} \mathrm{ml}^{-1}\right)$ and trypsin inhibitor $\left(10 \mu \mathrm{g} \mathrm{ml}^{-1}\right)$. Electrophoresis was carried out in $12 \%$ polyacrylamide gel with $4.5 \%$ stacking gel. After electrophoresis, proteins were transferred to a nitrocellulose membrane. The membrane was then probed with mouse monoclonal antibodies specific to $\mathrm{nm} 23-\mathrm{H} 1(1: 500)$, and then HRP-conjugated goat antimouse IgG (ICN Pharmaceuticals, OH, USA) $(1: 5000)$. The protein bands were visualised by exposing a X-Omat film (Eastman Kodak, NY, USA) with enhanced chemiluminescent reagent (PIERCE, IL, USA) to the membrane.

\section{Statistical analysis}

The relationships between $\mathrm{nm} 23-\mathrm{H} 1$ expression and each of clinicopathologic parameters, including histologic grade of malignancy, primary tumour size, lymph node involvement, distant metastasis, tumour recurrence, habits of betel nut-chewing and cigarette-smoking, were analysed by $\chi^{2}$ with Yates' correction or Fisher's exact test (when the expected number of any cell was fewer than five). Survival curves were plotted with the method of Kaplan-Meier (Kaplan and Meier, 1958). Statistical difference of survival between different groups was compared by a log-rank test (Peto and Pike, 1973). The joint effect of clinicopathologic factors was further tested in multivariate analysis using a Cox regression model (Peto and Pike, 1973). Statistical analysis was performed by using SPSS software (version 10.0, SPSS Inc., IL, USA). Statistical significance was set at $P$-value $<0.05$.

\section{RESULTS}

\section{Clinicopathologic characteristics}

The mean age of this study group was 49.7 years (range, 24-85 years) and male-female ratio was 5.6:1 (73 men and 13 women). The median follow-up was 35.5 months, ranging from 1 to 165 months. Up to the time of final statistical analysis, 49 of 86 patients (57\%) were well and alive. However, 35 patients died of OSCC carcinomatosis and two deaths were OSCC-unrelated. Therefore, only 84 patients' data were legitimate for survival analysis. The overall cumulative 1-, 3- and 5-year survival rates were 83, 66 and $56 \%$, respectively.

\section{Expression of nm23-H1}

Immunohistochemically, $\mathrm{nm} 23-\mathrm{H} 1$ was detected in $48.8 \%$. (42 of 86) of tumourous specimens. IHC staining for $\mathrm{nm} 23-\mathrm{Hl}$ was predominantly cytoplasmic (Figure 1). To further confirm the $\mathrm{nm} 23-\mathrm{Hl}$ expression in OSCC, immunoblotting was carried out to compare 10 pairs of tumourous and nontumourous counterparts. The result was shown in Figure 2 and $n m 23-\mathrm{H} 1$ was indicated as a 23-kDa band.

\section{Relationships between $\mathrm{nm} 23-\mathrm{Hl}$ expression and clinicopathologic variables}

Relationships between $\mathrm{nm} 23-\mathrm{Hl}$ expression and seven respective clinicopathologic variables, for example, histologic grade of malignancy, tumour size, lymph node involvement, distant metastasis, tumour recurrence, habits of betel nut-chewing and cigarette-smoking, were summarised in Table 1 . The nm23 expression correlated only with two clinicopathologic variables: tumour size and cigarette-smoking habit. In $65.6 \%$ (21 out of 32 ) of patients with larger-size primary tumours $(>4 \mathrm{~cm})$, while only in $38.9 \%$ (21out of 54 ) of those with smaller-size tumours $(\leqslant 4 \mathrm{~cm})$ were $\mathrm{nm} 23-\mathrm{Hl}$ positive $(P=0.03)$. Moreover, in patients with cigarette-smoking habit, $\mathrm{nm} 23-\mathrm{Hl}$ positive rate $(68 \%, 17$ out of 25$)$ was lower than those without this habit $(41 \%, 25$ out of 61$)$ and the difference was significant $(P=0.042)$. Although fewer patients with

\section{$\frac{1}{N T} \frac{2}{N T} \frac{3}{N T} \frac{4}{N T} \frac{5}{N T} \frac{6}{N T} \frac{7}{N T} \frac{8}{N T} \frac{9}{N T} \frac{10}{N T}$}

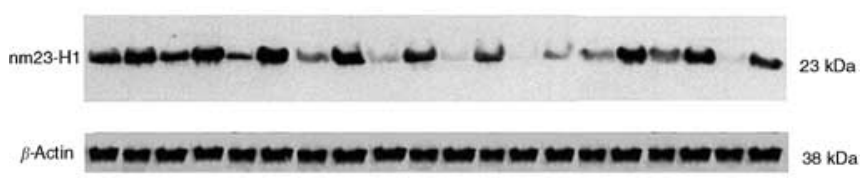

Figure 2 Immunoblotting analysis of $\mathrm{nm} 23-\mathrm{HI}$ expression in the tumourous $(\mathrm{T})$ and nontumourous $(\mathrm{N})$ tissue pairs from 10 patients with OSCC. Extracts from tumour cells or normal oral mucosa derived from the same patients were electrophoresed on a 12\% polyacrylamide gel with 4.5\% stacking gel. After transfer onto a nitrocellulose membrane, the proteins were immunoblotted with I:500 dilution of mouse monoclonal antibodies specific to $\mathrm{nm} 23-\mathrm{HI}$, followed by HRP-conjugated goat antimouse IgG and development for enhanced chemiluminescence. Molecular weight (in $\mathrm{kDa}$ ) is shown on the right.

nm23-Hl-positive OSCCs had cervical lymph node involvement (37.2 vs $62.8 \%)$ or distant metastasis (23.1 vs $76.9 \%)$ than those with nm23-H1-negative tumours, these differences were marginal ( $P=0.052$ and 0.086 , respectively). Nonetheless, nm23-Hl expression did not correlate with histologic grade of malignancy, tumour recurrence or betel nut-chewing habit.

\section{Effect evaluation of nm23-Hl in 54 OSCC patients at the early $\mathrm{T}$ stage}

When we analysed the data only from patients at the early $\mathrm{T}$ stages (tumour size $\leqslant 4 \mathrm{~cm}$ ), our results showed that the incidence of cervical lymph node involvement was indeed higher in the nm23$\mathrm{Hl}$ negative group $(51.5 \%, 17$ out of 33$)$ than the $\mathrm{nm} 23-\mathrm{Hl}$ positive group $(9.5 \%$, two out of 21$)$ and the difference was statistically significant $(P=0.004)$. Moreover, cigarette-smoking habit remained as a significant factor for suppressing nm23-Hl expression $(P=0.022)$ (Table 2). Otherwise, no significant correlation was found between $\mathrm{nm} 23-\mathrm{Hl}$ expression and the other clinicopathologic factors, for example, histologic grade, tumour recurrence, distant metastasis and betel nut-chewing habit.

\section{Survival analysis of 84 OSCC patients}

When all patients were divided into groups by each of clinicopathologic factors, significant difference by univariate analysis was shown in the following factors: tumour size $(P<0.001)$, lymph node involvement $(P<0.001)$, distant metastasis $(P<0.001)$, and tumour recurrence $(P<0.001)$ (Table 3$)$. In multivariate analysis, only tumour size $(P=0.002)$, distant metastasis $(P<0.001)$ and tumour recurrence $(P=0.040)$ remained significant. No statistical difference was found in histologic grade of malignancy, habits of betel nutchewing and cigarette-smoking, or nm23-H1 expression.

\section{Survival analysis of 53 OSCC patients at the early T stage}

When we analysed the data only from patients at the early $\mathrm{T}$ stages, statistical differences were found between survivals of two groups categorised by $\mathrm{nm} 23-\mathrm{H} 1$ expression $(P=0.014)$ (Figure 3 ) and cigarette-smoking habit $(P=0.032)$, in addition to lymph node involvement $(P=0.015)$, distant metastasis $(P<0.001)$ and tumour recurrence $(P=0.003)$. Nonetheless, in the multivariate analysis, only distant metastasis correlated with poor prognosis $(P=0.013)$. The results are summarised in Table 4.

\section{DISCUSSION}

Our results demonstrated that decreased $\mathrm{nm} 23$ expression in OSCC patients might correlate with tumour metastasis, which was 
Table I Relationship between nm23-HI expression and clinicopathologic parameters $(N=86)$

\begin{tabular}{|c|c|c|c|c|}
\hline Clinicopathologic parameter & Number of patients & \multicolumn{3}{|c|}{ Expression of $\mathrm{nm} 23-\mathrm{HI}$} \\
\hline \multicolumn{5}{|l|}{ Histologic grade of malignancy } \\
\hline Well-differentiated & 50 & $25(56.8)$ & $25(59.5)$ & 0.972 \\
\hline Moderately differentiated & 36 & $19(43.2)$ & $17(40.5)$ & \\
\hline \multicolumn{5}{|l|}{ Tumour size } \\
\hline \multicolumn{5}{|l|}{ Lymph node involvement } \\
\hline Negative & 43 & $17(38.6)$ & $26(61.9)$ & 0.052 \\
\hline Positive & 43 & $27(61.4)$ & $16(38.1)$ & \\
\hline \multicolumn{5}{|l|}{ Distant metastasis } \\
\hline Negative & 73 & $34(77.3)$ & $39(92.9)$ & 0.086 \\
\hline \multicolumn{5}{|l|}{ Tumour recurrence } \\
\hline Positive & 29 & $17(38.6)$ & $12(28.6)$ & \\
\hline \multicolumn{5}{|l|}{ Betel nut-chewing habit } \\
\hline Negative & 36 & $21(47.7)$ & $15(35.7)$ & 0.363 \\
\hline Positive & 50 & $23(52.3)$ & $27(64.3)$ & \\
\hline \multicolumn{5}{|l|}{ Cigarette-smoking habit } \\
\hline Negative & 25 & $8(18.2)$ & $17(40.5)$ & 0.042 \\
\hline Positive & 61 & $36(81.8)$ & $25(59.5)$ & \\
\hline
\end{tabular}

aPercentage of patients in the category. ${ }^{b} \chi^{2}$-test with Yates' correction.

Table 2 Relationship between nm23-HI expression and clinicopathologic parameters of patients with the early $\mathrm{T}$-stage OSCC (N=54)

\begin{tabular}{|c|c|c|c|c|}
\hline Clinicopathologic parameter & Number of patients & Negative (\%) ${ }^{\mathbf{a}}$ & Positive (\%) & $P^{\mathbf{b}}$ \\
\hline \multicolumn{5}{|l|}{ Histologic grade of malignancy } \\
\hline Well-differentiated & 33 & $21(63.6)$ & $12(57.1)$ & 0.849 \\
\hline Moderately differentiated & 21 & $12(36.4)$ & $9(42.9)$ & \\
\hline \multicolumn{5}{|l|}{ Lymph node involvement } \\
\hline \multicolumn{5}{|l|}{ Distant metastasis } \\
\hline Negative & 48 & $27(81.2)$ & $21(100)$ & 0.103 \\
\hline Positive & 6 & $6(18.2)$ & $0(0)$ & \\
\hline \multicolumn{5}{|l|}{ Tumour recurrence } \\
\hline Negative & 41 & $22(66.7)$ & $19(90.5)$ & 0.095 \\
\hline Positive & 25 & $15(45.5)$ & $10(47.6)$ & \\
\hline \multicolumn{5}{|l|}{ Cigarette-smoking habit } \\
\hline Negative & 15 & $5(15.2)$ & $10(47.6)$ & 0.022 \\
\hline Positive & 39 & $28(84.8)$ & II (52.4) & \\
\hline
\end{tabular}

aPercentage of patients in the category. ${ }^{\mathrm{b}} \chi^{2}$-test with Yates' correction.

frequently associated with poor prognosis. These data suggested that $\mathrm{nm} 23$ could serve as a marker for disease progression and prognosis in OSCC patients.

In the present study, we found that the positive rate of $\mathrm{nm} 23-\mathrm{H} 1$ expression was significantly higher in OSCCs at the late $\mathrm{T}$ stage
(T3, T4: tumour size $>4 \mathrm{~cm}$ ) than the early stage. Similarly, it has been indicated an association of $\mathrm{nm} 23$ overexpression with a larger tumour in neuroblastoma, thyroid, gastric and renal cell carcinomas (Hailat et al, 1991; Zou et al, 1993; Park et al, 1995; Müller et al, 1998). Increasing evidences have suggested that nm23 be 


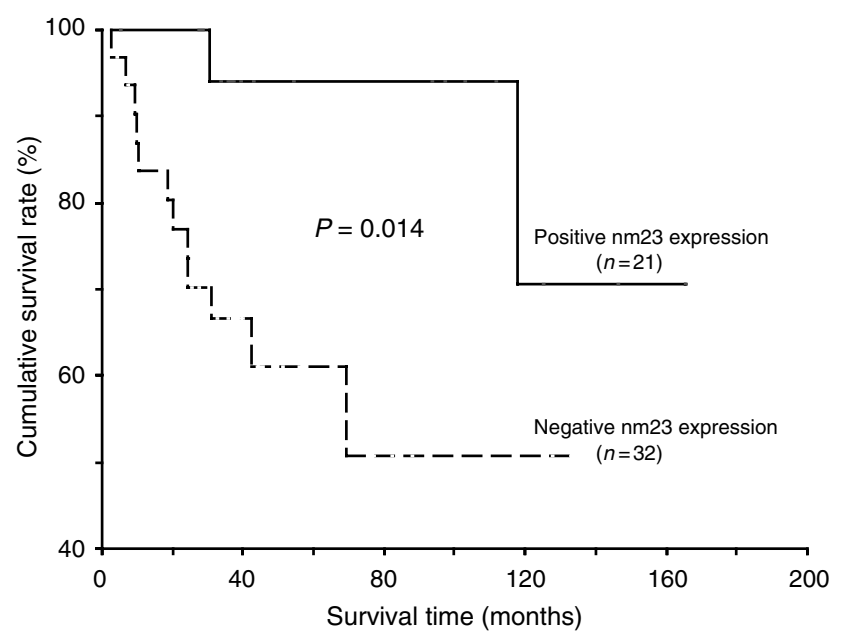

Figure 3 Overall survival curves of patients at the early T-stage OSCC in relation to tumour nm23-HI expression. The survival analysis was assessed by Kaplan-Meier method and the difference in survival between positive and negative $\mathrm{nm} 23-\mathrm{HI}$ expression groups was analysed by a log-rank test. The positive $\mathrm{nm} 23-\mathrm{HI}$ group had significantly better survival than the negative $\mathrm{nm} 23-\mathrm{HI}$ group $(P=0.014)$.

Table 3 Survival analysis of patients with $\operatorname{OSCC}(N=84)$

\begin{tabular}{|c|c|c|}
\hline \multirow[b]{2}{*}{$\begin{array}{c}\text { Clinicopathologic parameter (number } \\
\text { of patient analysed) }\end{array}$} & \multicolumn{2}{|c|}{$P$} \\
\hline & $\begin{array}{l}\text { Univariate } \\
\text { analysis }\end{array}$ & $\begin{array}{l}\text { Multivariate } \\
\text { analysis }\end{array}$ \\
\hline $\begin{array}{l}\text { Degree of differentiation } \\
\text { Well-differentiated (49) } \\
\text { Moderately (35) }\end{array}$ & 0.321 & \\
\hline $\begin{array}{l}\text { Tumour size } \\
\qquad \begin{array}{l}\mathrm{T} I+\mathrm{T} 2(\leqslant 4 \mathrm{~cm})(53) \\
\mathrm{T} 3+\mathrm{T} 4(>4 \mathrm{~cm})(3 \mathrm{I})\end{array}\end{array}$ & $<0.001$ & 0.002 \\
\hline $\begin{array}{l}\text { Lymph node involvement } \\
\text { Negative (42) } \\
\text { Positive (42) }\end{array}$ & $<0.001$ & 0.747 \\
\hline $\begin{array}{l}\text { Distant metastasis } \\
\text { Negative }(7 \mathrm{I}) \\
\text { Positive }(13)\end{array}$ & $<0.001$ & $<0.001$ \\
\hline $\begin{array}{l}\text { Tumour recurrence } \\
\text { Negative }(55) \\
\text { Positive (29) }\end{array}$ & $<0.001$ & 0.040 \\
\hline $\begin{array}{l}\text { Betel nut-chewing habit } \\
\text { Negative (36) } \\
\text { Positive (48) }\end{array}$ & 0.173 & \\
\hline $\begin{array}{l}\text { Cigarette-smoking } \\
\text { Negative }(25) \\
\text { Positive (59) }\end{array}$ & 0.330 & \\
\hline $\begin{array}{l}\text { nm23-HI expression } \\
\text { Negative (43) } \\
\text { Positive (4I) }\end{array}$ & 0.150 & \\
\hline
\end{tabular}

involved in cell growth and microtubule mitotic spindle polymeration in S phase (Igawa et al, 1994; Caligo et al, 1995). Cipollini et al. (1997) also reported that downregulation of nm23 gene inhibited cell proliferation. However, not all of the above studies demonstrated a negative prognostic impact of nm23 overexpres-
Table 4 Survival analysis of patients with the early T-stage OSCC $(N=53)$

\begin{tabular}{|c|c|c|}
\hline \multirow[b]{2}{*}{$\begin{array}{l}\text { Clinicopathologic parameter (number } \\
\text { of patient analysed) }\end{array}$} & \multicolumn{2}{|c|}{$P$} \\
\hline & $\begin{array}{l}\text { Univariate } \\
\text { analysis }\end{array}$ & $\begin{array}{l}\text { Multivariate } \\
\text { analysis }\end{array}$ \\
\hline $\begin{array}{l}\text { Degree of differentiation } \\
\text { Well-differentiated (32) } \\
\text { Moderately }(2 \mathrm{I})\end{array}$ & 0.443 & \\
\hline $\begin{array}{l}\text { Lymph node involvement } \\
\text { Negative (34) } \\
\text { Positive (19) }\end{array}$ & 0.015 & 0.911 \\
\hline $\begin{array}{l}\text { Distant metastasis } \\
\text { Negative (47) } \\
\text { Positive (6) }\end{array}$ & $<0.001$ & 0.013 \\
\hline $\begin{array}{l}\text { Tumour recurrence } \\
\text { Negative (40) } \\
\text { Positive (13) }\end{array}$ & 0.003 & 0.208 \\
\hline $\begin{array}{l}\text { Betel nut-chewing habit } \\
\text { Negative (29) } \\
\text { Positive (2I) }\end{array}$ & 0.106 & \\
\hline $\begin{array}{l}\text { Cigarette-smoking } \\
\text { Negative (15) } \\
\text { Positive (38) }\end{array}$ & 0.032 & 0.165 \\
\hline $\begin{array}{l}\text { nm23-HI expression } \\
\text { Negative (32) } \\
\text { Positive (2I) }\end{array}$ & 0.014 & 0.230 \\
\hline
\end{tabular}

sion or late T stage tumours (Zou et al, 1993; Müller et al, 1998). There were also some discrepancies among previous studies of the same tumours, such as gastric and colorectal cancers (Cohn et al, 1991; Haut et al, 1991; Kodera et al, 1994; Müller et al, 1998). Concerning gastric cancers, Kodera et al (1994) reported that a negative prognostic impact of decreased $\mathrm{nm} 23$ expression might correlated with increased lymphatic metastasis; while Müller et al (1998) showed nm23 overexpression was associated with aggressive tumour growth and poor survival. It is possible that $\mathrm{nm} 23$ could play variable roles in different molecular events and contribute to distinct outcomes. These results certainly need further investigations.

As noted previously, $\mathrm{nm} 23$, originally identified from a weakly metastatic cancer cells, was found to have antimetastatic potential in human carcinomas (Bevilacqua et al, 1989; Caligo et al, 1997). Since clinical prognosis of OSCC patients is closely associated with lymphatic spread and distant metastasis (Wang et al, 2002), it is reasonable to hypothesise that $\mathrm{nm} 23$ may play some role in disease progression of OSCC. Song et al, (2000) demonstrated that the increase of $\mathrm{nm} 23$ expression correlated with decreased incidence of lymph node metastasis in patients with head and neck cancers, though Pavelic et al (2000) revealed a different result in patients with the advanced disease. Such a variation may be due to heterogeneity of primary tumour distribution, methods of investigation and scoring systems for pathological variables. By showing that patients with larger OSCCs $(>4 \mathrm{~cm})$ mostly have $\mathrm{nm} 23-\mathrm{H} 1$ positive tumours, the current study indicated that $\mathrm{nm} 23$ might also be associated with cell proliferation (Caligo et al, 1995; Cipollini et al, 1997). Many studies have reported that late-stage cancer could obtain more metastatic ability by increasing events contributing to tumor spreading, such as angiogenesis, adhesion, proteolysis and motility (Petruzzelli et al, 1998; Bashyam, 2002). To avoid such interference, that increased size of primary tumour 
could escalate metastatic potential and then the data of patients at the late $\mathrm{T}$ stage might confound statistical analyses, we therefore particularly emphasised our analysis on patients at the early $\mathrm{T}$ stage. Our results indicated that $\mathrm{nm} 23-\mathrm{H} 1$-negative OSCCs indeed had a significantly higher incidence of lymph node metastasis at the early $\mathrm{T}$ stage. However, such correlation was equivocal at the late $\mathrm{T}$ stage (Table 1 and 2). These results suggested that the role of $\mathrm{nm} 23-\mathrm{H} 1$ in OSCCs at early $\mathrm{T}$ stage, including carcinogenesis, be different from that at late $\mathrm{T}$ stage, when the adjuvant therapy should be applied (Bevilacqua et al, 1989; Caligo et al, 1997; Cipollini et al, 1997; Pavelic et al, 2000; Song et al, 2000). As genetic instability altering with disease progression is one important character of malignant tumour, it is possible that $\mathrm{nm} 23-\mathrm{H} 1$ play various roles in the different stages of cancer development.

In fact, by an immunohistochemical study, Ohtsuki et al (1997) had demonstrated that OSCCs with positive nm23 expression was related with a lower incidence of lymph node metastasis. Lo Muzio et al (1999) further showed that this nm23 was nm23-H1. Our results supported their findings, in particular regarding patients at the early $\mathrm{T}$ stage; these data clearly indicated that $\mathrm{nm} 23-\mathrm{H} 1$ expression could have antimetastatic potential and prognostic significance in OSCC patients. Moreover, in addition to lymph node involvement, we evaluated the correlations of nm23 expression with occurrence of distant metastasis. Although statistical difference was not reached $(P=0.086)$, a marginally higher metastatic incidence was observed in the $\mathrm{nm} 23-\mathrm{H} 1$ negative group $(22.7 \%, 10$ out of 44$)$ compared with that in the nm23-H1 positive group ( $7.1 \%$, three out of 42$)$. As a matter of fact that the influence of $\mathrm{nm} 23-\mathrm{H} 1$ expression was clearly showed in the univariate analysis on OSCC patients at the early $\mathrm{T}$ stage, in which the survival of the $\mathrm{nm} 23-\mathrm{H} 1$ positive group was significantly better than that of the negative group. However, we could not found the similar result in patients at the advanced $\mathrm{T}$ stage. A larger study cohort is required to conclusively determine the effect of nm23-H1 expression on lymph node involvement, distant metastasis and cell proliferation, which may ultimately predict therapeutic response and survival.

In our results, it is worth noting that cigarette smoking might inhibit nm23-H1 expression and relate to poor survival for OSCC patients at the early $\mathrm{T}$ stage by univariate analysis. This effect on patients' prognosis was not obvious in the multivariate analysis. Our data indicated that smoking habit might be closely associated with cancer development and metastasis at the early $\mathrm{T}$ stage, but smoking alone was not a predicting factor for patients' response to adjuvant chemoradiotherapy at the late stage (Bundgaard et al, 1994). Furthermore, recent studies reported that mutagenicity of tobacco smoke might have some influence on biologic behaviors of OSCCs through DNA alterations, including K-ras oncogene and p53 mutation (Westra et al, 1993; Hsieh et al, 2001). The relationships between $\mathrm{nm} 23-\mathrm{H} 1$ expression and specific molecular targets of tobacco carcinogens need more investigation.

Recently, an elegant study by Iizuka et al (2000) supported a possibility by demonstrating that reduced $\mathrm{nm} 23$ expression could increase cisplatin resistance. These authors showed that downregulation of $\mathrm{nm} 23-\mathrm{H} 1$ expression could decrease intracellular cisplatin accumulation probably via altered $\mathrm{Na}^{+}, \mathrm{K}^{+}$-ATPase activity. If, as suggested by the above data, the nm23-H1associated antimetastatic potential might be closely in company with chemosensitivity; it is possible that less $\mathrm{nm} 23-\mathrm{H} 1$ expression and hence higher cisplatin resistance may lead to poorer survival. Previous literature reported that metastatic tumors seemed more resistant to chemoradiotherapy (McKenna et al, 1990; Herbst and Langer, 2002; Real et al, 2002) and it might result from the common molecular mechanisms shared by both cancer metastasis and chemoradioresistance. The lack of nm23 expression in cancer cells might be another pathway leading to both events and has the potential of being a clinically prognostic predictor for chemoradiotherapy. In our series, local irradiation and/or systemic cisplatin-based chemotherapy were administered for the patients with metastatic cancers over cervical lymph nodes or distant organs. Referred to our database of OSCC patients, we will further study the role of $\mathrm{nm} 23$ in chemoradiosensitivity.

Our results revealed that there was no relationship between $\mathrm{nm} 23-\mathrm{H} 1$ expression and betel nut-chewing. A working group of the International Agency for Research on Cancer (IARC) concluded that evidence supporting a link between betel nutchewing alone and human oral cancer was not sufficient (IARC, 1986). Buccal cancers were reported more frequently found in patients with betel nut-chewing habits (Thomas and MacLennan, 1992). However, tongue was only associated with cancers of smokers and the most common site among patients without any oral habits (Silverman and Griffith, 1972; Chen et al, 1999). In our series, there were very few OSCC patients with betel nut-chewing habit alone but without smoking (seven out of $86=8 \%$ ) and most tumors were located on the tongue ( 58 out of $86=67 \%$ ). Previous data reported that lingual cancers occurred less frequently in patients with betel nut-chewing habit alone (Ko et al, 1995; Chen et al, 1999). Furthermore, Taiwanese betel nuts do not contain tobacco and are different from those in India, where betel nuts nearly always include tobacco, a known cause of oral cancer. The above observations may explain the result that there was no significant relationship between $\mathrm{nm} 23 \mathrm{H} 1$ expression and the betel nut-chewing habit in our study.

In conclusion, our results showed that $\mathrm{nm} 23-\mathrm{H} 1$ was frequently expressed in pathologic specimens of OSCC. Nm23-H1 overexpression correlated with larger primary tumour size. In patients at the early $\mathrm{T}$ stage, increased $\mathrm{nm} 23$ expression was associated with decreased incidence of lymph node involvement, which in turn showed a better prognosis. This effect was suggested due to antimetastatic potential and the role in chemoradiosensitivity of nm23-H1. Nevertheless, other explanations are possible. The mechanisms of nm23-H1 about cancer metastasis and cytotoxicity of chemoradiation remain to be determined conclusively.

\section{ACKNOWLEDGEMENTS}

WeE are grateful for the technical assistance of Ms Li-Ling Yang and Yi-Hsiu Kuo. This study was supported by the grants from Taipei Veterans General Hospital (VGH93-073), Lite-on Cultural Foundation (LF2003MD01) and National Science Council (NSC922314-B-075-076), Taiwan.

\section{REFERENCES}

Anneroth G, Batsakis J, Luna M (1987) Review of the literature and a recommended system of malignancy grading in oral squamous cell carcinomas. Scand J Dent Res 95: 229-249

Barnes R, Masood S, Barker E, Rosengard AM, Coggin DL, Crowell T, King CR, Porter-Jordan K, Wargotz ES, Liotta LA, Steeg PS (1991) Low nm23 protein expression in infiltrating ductal breast carcinomas correlates with reduced patient survival. Am J Pathol 139: 245-250
Bashyam MD (2002) Understanding cancer metastasis. Cancer 94: $1821-1829$

Bevilacqua G, Sobel ME, Liotta LA, Steeg PS (1989) Association of low nm23 levels in human primary infiltrating ductal breast carcinomas with lymph node involvement and other histopathological indicators of high metastatic potential. Cancer Res 49: $5185-5190$ 
Bundgaard T, Bentzen SM, Wildt J (1994) The prognostic effect of tobacco and alcohol consumption in intra-oral squamous cell carcinoma. Oral Oncol Eur J Cancer 30B: 323-328

Caligo MA, Cipollini G, Berti A, Viacava P, Collecchi P, Bevilacqua G (1997) NM23 gene expression in human breast carcinomas: loss of correlation with cell proliferation in the advanced phase of tumor progression. Int $J$ Cancer 74: $102-111$

Caligo MA, Cipollini G, Cope Di Valromita A, Bistocchi M, Bevilacqua G (1992) Decreasing expression of NM23 gene in metastatic murine mammary tumors of viral etiology (MMTV). Anticancer Res 12: 969-974

Caligo MA, Cipollini G, Fiore L, Calvo S, Basolo F, Collecchi P, Ciardiellon F, Pepe S, Petrini M, Bevilacqua G (1995) NM23 gene expression correlates with cell growth rate and S-phase. Int J Cancer 60: 837-842

Campo E, Miquel R, Jares P, Bosch F, Juan M, Leone A, Vives J, Cardesa A, Yague J (1994) Prognostic significance of the loss of heterozygosity of nm23-H1 and p53 genes in human colorectal carcinomas. Cancer 73: 2913-2921

Chen YK, Huang HC, Lin LM, Lin CC (1999) Primary oral squamous cell carcinoma: an analysis of 703 cases in southern Taiwan. Oral Oncol 35: $173-179$

Cipollini G, Berti A, Fiore L, Rainaldi G, Basolo F, Merlo G, Bevilacqua G, Caligo MA (1997) Down-regulation of the nm23.hl gene inhibits cell proliferation. Int J Cancer 73: 297-302

Cohn KH, Wang FS, Patterson LG, Arnold MR, Weimar J, Solomon WB, Feldman JG, Desoto-LaPaix F, Levy AT, Leone A, Steeg PS (1991) Association of $\mathrm{nm} 23-\mathrm{H} 1$ allelic deletions with distant metastases in colorectal carcinoma. Lancet 338: 722-724

Fleming ID, Cooper JS, Henson DE, Hutter RV, Kennedy BJ, Murphy GP, O'Sullivan B, Sorbin LH, Yarbro JW (eds ) (1997) AJCC Cancer Staging Manual, pp 24-30. Philadelphia: Lippincott-Raven

Gilles A-M, Presecan E, Vonica A, Lascu I (1991) Nucleoside diphosphate kinase from human erythrocytes. Structural characterization of the two polypeptide chains responsible for heterogeneity of the hexameric enzyme. J Biol Chem 266: 8784-8789

Hailat N, Keim DR, Melhelm RF, Zhu XX, Eckerskorn C, Brodeur GM, Reynolds CP, Seeger RC, Lottspeich F, Strahler JR, Hanash SM (1991) High levels of $\mathrm{p} 19 / \mathrm{nm} 23$ protein in neuroblastoma are associated with advanced stage disease and with $\mathrm{n}$-myc gene amplication. $J$ Clin Invest 88: $341-345$

Haut M, Steeg PS, Willson JK, Markowitz SD (1991) Induction of nm23 gene expression in human colonic neoplasms and equal expression in colon tumors of high and low metastatic potential. J Natl Cancer Inst 83: $712-716$

Herbst RS, Langer CJ (2002) Epidermal growth factors as a target for cancer treatment: the emerging role of IMC-C225 in the treatment of lung and head and neck cancers. Semin Oncol 29: 27-36

Hirayama R, Sawai S, Takagi Y, Mishima Y, Kimura N, Shimada N, Esaki Y, Kurashima C, Utsuyama M, Hirokawa K (1991) Positive relationship between expression of anti-metastatic factor (nm23 gene product or nucleoside diphosphate kinase) and good prognosis in human breast cancer. J Natl Cancer Inst 83: 1249-1250

Hsieh LL, Wang PF, Chen IH, Liao CT, Wang HM, Chen MC, Chang JTC, Cheng AJ (2001) Characteristics of mutations in the p53 gene in oral squamous cell carcinoma associated with betel quit chewing and cigarette smoking in Taiwanese. Carcinogenesis 22: 1497-1503

Hsu NY, Chow KC, Chen WJ, Lin CC, Chou FF, Chen CL (1999) Expression of $\mathrm{nm} 23$ in the primary tumor and the metastatic regional lymph nodes of patients with gastric cardiac cancer. Clin Cancer Res 5: $1752-1757$

IARC (1986) Betel-quid and areca-nut chewing. Monographs, I nternational Agency for Research on Cancer, Lyon, Vol 37, pp 141-297

Igawa M, Rukstalis DB, Tanabe T, Chodak GH (1994) High levels of nm23 expression are related to cell proliferation in human prostate cancer. Cancer Res 54: 1313-1318

Iizuka N, Miyamoto K, Tangoku A, Hayashi H, Hazama S, Yoshino S, Yoshimura K, Hirose K, Yoshida H, Oka M (2000) Downregulation of intracellular $\mathrm{nm} 23-\mathrm{H} 1$ prevents cisplatin-induced DNA damage in oesophageal cancer cells: possible association with $\mathrm{Na}^{+}, \mathrm{K}^{+}$-ATPase. $\mathrm{Br}$ J Cancer 83: 1209-1215

Kaplan EL, Meier P (1958) Nonparametric estimation from incomplete observations. Am Stat Assoc J 53: $457-481$

Ko YC, Huang YL, Lee CH, Chen MJ, Lin LM, Tsai CC (1995) Betel quit chewing, cigarette smoking and alcohol consumption related to oral cancer in Taiwan. J Oral Pathol Med 24: $450-453$
Kodera Y, Isobe KI, Yamauchi M, Kondoh K, Kimura N, Akiyama S, Itoh K, Nakashima I, Takagi H (1994) Expression of nm23-H1 RNA levels in human gastric cancer tissues. Cancer 73: 259-265

Lacombe M-L, Milon L, Munier A, Mehus JG, Lambeth DO (2000) The human nm23/nucleoside diphosphate kinases. J Bioenerg Biomembranes 32: $247-258$

Lo Muzio L, Mignogna M, Pannone G, Staibano S, Procaccini M, Serpico R, De Rosa G, Scully C (1999) The NM23 gene and its expression in oral squamous cell carcinoma. Oncol Rept 6: $747-751$

McKenna WG, Weiss MC, Bakanauskas VJ, Sandler H, Kelsten ML, Biaglow J, Tuttle SW, Endkich B, Ling CC, Muschel RJ (1990) The role of the $\mathrm{H}$-ras oncogene in radiation resistance and metastasis. Int J Radiat Oncol Biol Phys 18: 849-859

Moskaluk CA (2002) Standardization of clinical immunohistochemistry. Am J Clin Pathol 118: 669-671

Müller W, Schneiders A, Hommel G, Gabbert HE (1998) Expression of $\mathrm{nm} 23$ in gastric carcinoma associated with tumor progression and poor prognosis. Cancer 83: $2481-2487$

Nakayama T, Ohtsuru A, Nakao K, Shima M, Nakata K, Watanabe K, Ishii N, Kimura N, Nagataki S (1992) Expression in human hepatocellular carcinoma of nucleoside diphosphate kinase, a homologue of the nm23 gene product. J Natl Cancer Inst 84: $1349-1354$

Ohtsuki K, Shintani S, Kimura N, Matsumura T (1997) Immunohistochemical study on nm23 gene product (NDP Kinase) in oral squamous cell carcinoma. Oral Oncol 33: 237-239

Park DS, Cho NH, Lee YT, Park C, Lee JM (1995) Analysis of nm23 expression as a prognostic parameter in renal cell carcinoma. J Korean Med Sci 10: $258-262$

Paveliæ K, Kapitanoiæ S, Radoševiæ S, Bura M, Seiwerth S, Paveliæ LJ, Unušiæ J, Spaventi R (2000) Increased activity of $\mathrm{nm} 23-\mathrm{Hl}$ gene in squamous cell carcinoma of the head and neck is associated with advanced disease and poor prognosis. J Mol Med 78: 111-118

Peto R, Pike MC (1973) Conservatism of the approximation $\Sigma(O-E)^{2} / E$ in the Logrank test for survival data or incidence data. Biometrics 29: $579-584$

Petruzzelli GJ, Benefield J, Yong S (1998) Mechanism of lymph node metastases: current concepts. Otolaryngol Clin $N$ Am 31: $585-599$

Pindborg JJ (1977) Epidemiological studies of oral cancer. Intern Dent J 27: $172-178$

Real PJ, Sierra A, De Juan A, Segovia JC, Lopez-Vega JM, Fernadez-Luna JL (2002) Resistance to chemotherapy via Stat3-dependent overexpression of Bcl-2 in metastatic breast cancer cells. Oncogene 21: $7611-7618$

Sankaranarayanan R (1990) Oral cancer in India: an epidemiologic and clinical review. Oral Surg Oral Med Oral Pathol 69: 325-330

Scully C, Porter S (2000) Oral Cancer. BMJ 321: 97-100

Silverman Jr S, Griffith M (1972) Smoking characteristics of patients with oral carcinoma and risk for second oral primary carcinoma. JADA 85: $637-640$

Song AU, Mais DD, Groo S, Wright JR, Yoshida GY (2000) Expression of nm23 antimetastatic gene product in head and neck squamous cell carcinoma. Otolaryngol Head Neck Surg 122: 96-99

Stahl JA, Leone A, Rosengard AM, Porter L, King CR, Steeg PS (1991) Identification of a second human $\mathrm{nm} 23$ gene, $\mathrm{nm} 23-\mathrm{H} 2$. Cancer Res 51: $445-449$

Steeg PS, Bevilacqua G, Kopper L, Thorgeirsson UP, Talmadge JE, Liotta LA, Sobel ME (1988a) Evidence for a novel gene associated with low tumor metastatic potential. J Nat Cancer Inst 80: 200-204

Steeg PS, Bevilacqua G, Pozzatti R, Liotta LA, Sobel ME (1988b) Altered expression of NM23, a gene associated with low tumor metastatic potential, during adenovirus 2 Ela inhibition of experimental metastasis. Cancer Res 48: 6550-6554

Thomas SJ, MacLennan R (1992) Slaked lime and betel nut cancer in Papua New Guinea. Lancet 340: $577-578$

Tsay CH, Chiu CH (1990) An epidemiological study of oral cancer in Taiwan. Chin Dent J 9: 104-115

Wang LS, Chow KC, Chi KH, Liu CC, Li WY, Chiu JH, Huang MH (1999a) Prognosis of esophageal squamous cell carcinoma: analysis of clinicopathological and biological factors. Am J Gastroenterol 94: $1933-1940$

Wang LS, Chow KC, Wu CW (1999b) Expression and upregulation of interleukin- 6 in esophageal carcinoma cells by n-sodium butyrate. $\mathrm{Br} \mathrm{J}$ Cancer 80: $1617-1622$ 
nm23-HI in oral cancer

Y-F Wang et al

Wang YF, Chang SY, Tai SK, Li WY, Wang LS (2002) Clinical significance of interleukin-6 and interleukin-6 receptor expressions in oral squamous cell carcinoma. Head Neck 24: 850-858

Westra WH, Slebos RJC, Offerhaus GJA, Goodman SN, Evers SG, Kensler TW, Askin FB, Rodenhuis S, Hruban RH (1993) K-ras oncogene activation in lung adenocarcinomas from former smokers. Cancer 72: $432-438$

Zakrzewska JM (1999) Fortnightly review: oral cancer. BMJ 318: 1051 - 1054

Zou M, Shi Y, Al-Sedaery S, Farid NR (1993) High levels of nm23 gene expression in advanced stage of thyroid carcinomas. Br J Cancer 68: $385-388$ 